\title{
INFLUENCE OF A INFRASTRUCTURE ON TSUNAMI INUNDATION IN A COASTAL CITY: LABORATORY EXPERIMENT AND NUMERICAL SIMULATION
}

\author{
Sungwon Shin ${ }^{1}$, Kwang-Ho Lee ${ }^{1}$, Hyungsu Park ${ }^{2}$, Daniel T. Cox², Kyuhan Kim ${ }^{1}$ \\ Laboratory experiments were conducted for tsunami inundation to an urban area with large building roughness. The \\ waterfront portion of the city of Seaside which is located on the US Pacific Northwest coast, was replicated in 1/50 \\ scale in the wave basin. Tsunami heights and velocities on the inundated land were measured at approximately 31 \\ locations for one incident tsunami heights with an inundation height of approximately $10 \mathrm{~m}$ (prototype) near the \\ shoreline. The inundation pattern and speed were more severe and faster in some areas due to the arrangement of the \\ large buildings. Momentum fluxes along the roads were estimated using measure tsunami inundation heights and \\ horizontal fluid velocities. As expected, the maximum momentum flux was near the shoreline and decreased landward. \\ 3D LES (Large Eddy Simulation) model with two-phase flow was used to compare its simulation results with \\ experimental results. The model results of tsunami heights qualitatively agreed with the data collected from the \\ experiment
}

Keywords: tsunami, inundation, experiment, numerical modeling, large eddy simulation. and momentum flux

\section{INTRODUCTION}

Several tsunami events occurred recently remind us the importance of understanding the physics of tsunami to protect human lives and properties in coastal cities. Especially, understanding tsunami inundation is very important to reduce the damage to coastal infrastructures. Many researchers conducted post-survey in the site that tsunami attacked. However, it is almost impossible to obtain data set of hydrodynamics, i.e. time history of inundation and flow velocity even if they are necessary to verify numerical models.

During the last decade, modeling of tsunami inundation has significantly evolved into mature numerical techniques and some models are now capable of simulating tsunami inundation for complex three-dimensional shoreline topography. However, fewer models (Tomita et al., 2007; Lynett, 2007) are able to simulate complex overland flows, and the flow pattern around groups of buildings remains a challenging area of research (Cox et al. 2008).

Numerical models require field observation data and physical model data to validate their modeling capability. Since field observations during the inundation process are limited to video data, laboratory measurements are very important for providing quantitative detailed data for model validation. Rueben, et al. (2011) conducted large-scale laboratory experiments using optical measurement methods to investigate tsunami inundation phenomena in an urban area near a coast. In their experiments, the complex groups of buildings modified the flow pattern and the macro-roughness reduced the inundation speed.

In this study, laboratory experiments for tsunami inundation are extended to an urban area with large building roughness (Figure 1, left). The experiments were conducted in a three-dimensional wave basin with a scale of $26.5 \mathrm{~m}$ (width) x $48.8 \mathrm{~m}$ (length) x $2.1 \mathrm{~m}$ (depth). 29 piston type wave boards in the basin are controlled independently to generate various types of ocean waves and tsunamis. The waterfront portion of the city of Seaside which is located on the US Pacific Northwest coast, was replicated in 1/50 scale in the wave basin. Tsunami heights and velocities on the inundated land were measured at approximately 31 locations (Figure 1, right) for one incident tsunami heights replicating the 500 year Cascadia Subduction Zone event with an inundation height of approximately $10 \mathrm{~m}$ (prototype) near the shoreline. Incident wave heights measured using capacitance and ultrasonic wave gages, and tsunami front velocities were measured by video images and acoustic-Doppler current meters. This study focused on the momentum flux $\left(h u^{2}\right)$ since this can be related to the base shear by the tsunami on the buildings.

3D LES (Large Eddy Simulation) model with two-phase flow was developed by Lee, et al (2010). This model has been validated through laboratory experiments on coastal structures such as breakwaters. In this study, this model was preliminarily tested to predict tsunami inundation heights over the urban area as a function of time.

Therefore, the basic goals of this study were to:

1. Obtain synoptic data set for tsunami inundation for numerical model verification.

\footnotetext{
${ }^{1}$ Waterfront and Coastal Research Center, Kwandong University, Gangneung, Gangwond-do,201-701, South Korea

${ }^{2}$ Civil and Construction Engineering, Oregon State University, Corvallis, Oregon, 97331, U.S.A.
} 
2. Estimate momentum flux using inundation height and horizontal fluid velocity data.

3. Test numerical model (3D LES model) capability to simulate inundation height, horizontal velocity, and momentum flux in complex coastal city.
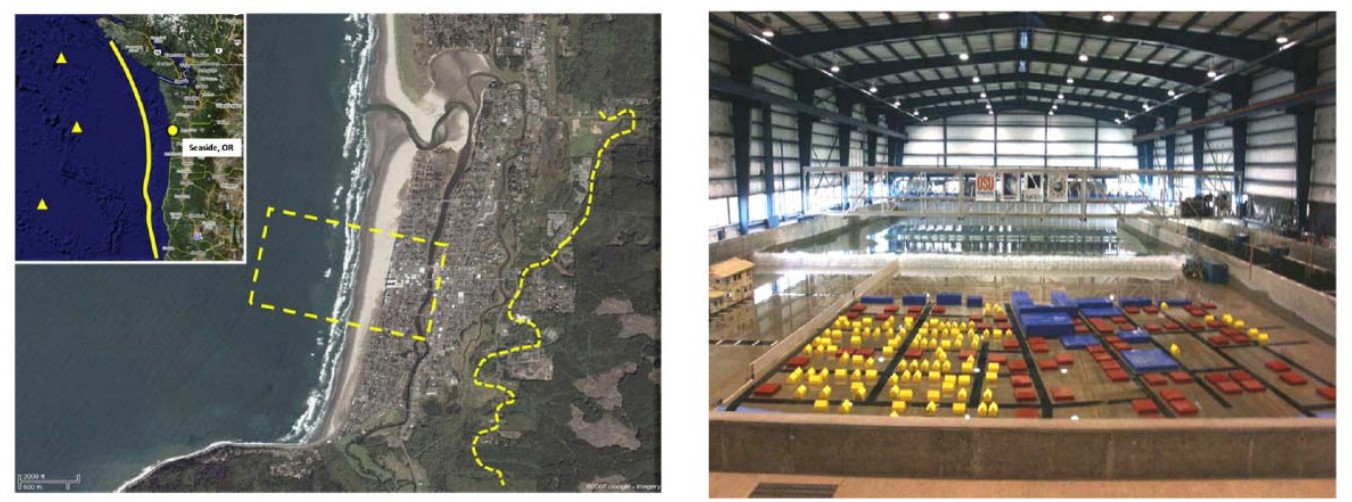

Figure 1. Site map of the experiment, Seaside, Oregon (left); 1:50 scale idealized model of Seaside (right)

\section{EXPERIMENTAL CONDITIONS}

The experiments were conducted in the Tsunami Wave Basin at the O.H. Hinsdale Wave Research Laboratory, Oregon State University. The size of basin is $48.8 \mathrm{~m}$ long by $26.5 \mathrm{~m}$ wide by $2.1 \mathrm{~m}$ deep equipped with a segmented, piston-type wavemaker with a maximum stroke of $2.1 \mathrm{~m}$ and maximum velocity of $2.0 \mathrm{~m} / \mathrm{s}$. This wavemaker was specifically designed to generate precise, solitary waves for tsunami research. As mentioned in Cox, et al (2008), two different types of waves, tsunami using error function and solitary wave, were generated. This study used the data collected by using an error function designed to maximize the full stroke of the wavemaker while limiting the offshore wave height to $20 \mathrm{~cm}$. Baldock, et al. (2009) also used this type of wave instead of solitary wave to figure out the kinematics of breaking tsunami wave front and runup on the beach. This wave height corresponded to the $10 \mathrm{~m}$ height in prototype scale estimated for the "500-yr" Cascadia Subduction Zone tsunami for this region (USGS 2006).

\begin{tabular}{|c|c|c|c|c|}
\hline Case & $\mathrm{H}(\mathrm{cm})$ & No. of trials & Wave type & Comment \\
\hline 1 & 20 & 134 & ERF & 500 yr event \\
\hline 2 & $10-50$ & 20 & Solitary & Sea Wall \\
\hline 3 & $10-50$ & 20 & Solitary & Dune fronting sea wall \\
\hline
\end{tabular}

The identical tsunami was repeated 134 times, with three sensor pairs moved along transects corresponding to major streets. The idealized bathymetry was shore parallel consisting of a constant depth section near the wavemaker, a 1:15 rise followed by a mild 1:30 slope, leading to anotheflat section on which the idealized buildings (colored blocks) were added and fixed (Figure 2). The seawall was also idealized in the model as $4 \mathrm{~cm}$ high ( $2 \mathrm{~m}$ height in prototype) alongshore uniform. Detailed information of the building setup was described by Cox, et al. (2008) and Ruben, et al. (2011). All elements werefixed in place to allow repeated runs of the experiment with the same macro-roughness conditions, and a LIDAR survey was taken to quantify the location of all the roughness elements to construct the boundary conditions for numerical models (e.g., Cox et al., 2008).

In order to measure wave heights and wave velocities, four resistance type wave gages (WG, here in after), four ultrasonic wave gages (USWG, here in after), and four acoustic Doppler velocimeters (ADV) were used in this experiment as shown in Figure 2. All resistance wave gages were fixed on the bottom for the entire period of the experiment. WG1 and WG2 were installed on the flat bottom near the wavemaker to check offshore tsunami heights for every single run. WG3 and WG4 were mounted on the 1:35 slope to check tsunami height variation due to shoaling effect. 


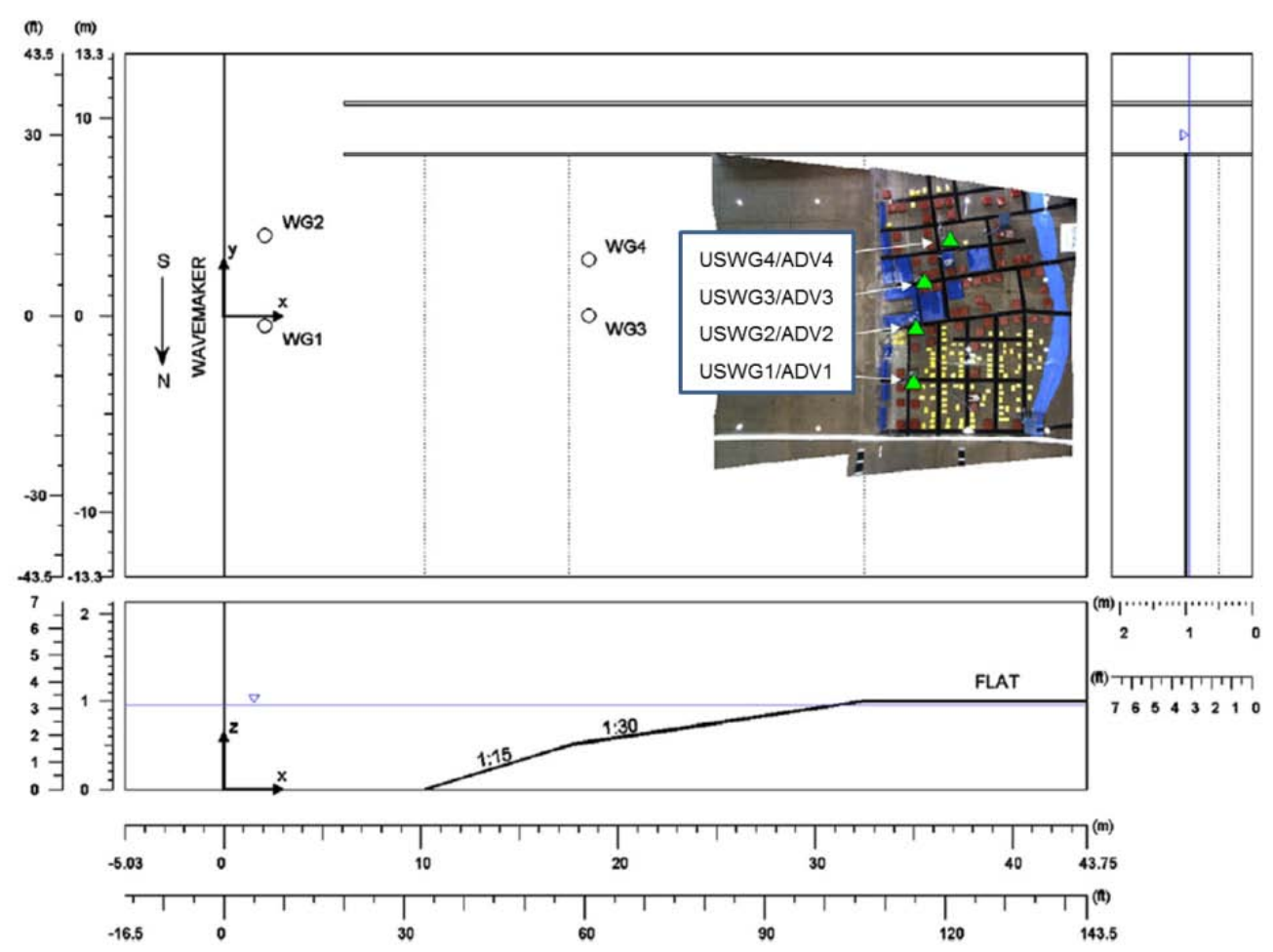

Figure 2. A schematic view of experimental setup and instrumentation. "WG" stands for resistance type wave gage and "USWG" stands for ultrasonic wave gage. USWGs were collocated with ADVs to estimate momentum flux.

Four pairs of collocated USWGs and ADVs were installed and measured inundation heights and fluid velocities along the major roads in the site to investigate cross-shore variations of those quantities. The measurements by using collocated USWGs and ADVs were repeated $7 \sim 50$ times at each location and moved the instruments to next position. Figure 3 shows the measurement locations of inundation heights and fluid velocities. In this figure, we can see that street A and B are formed as waveguides by series of buildings compared to street A and D. All the data were collected with the sampling rate of 50 $\mathrm{Hz}$ and synchronized.

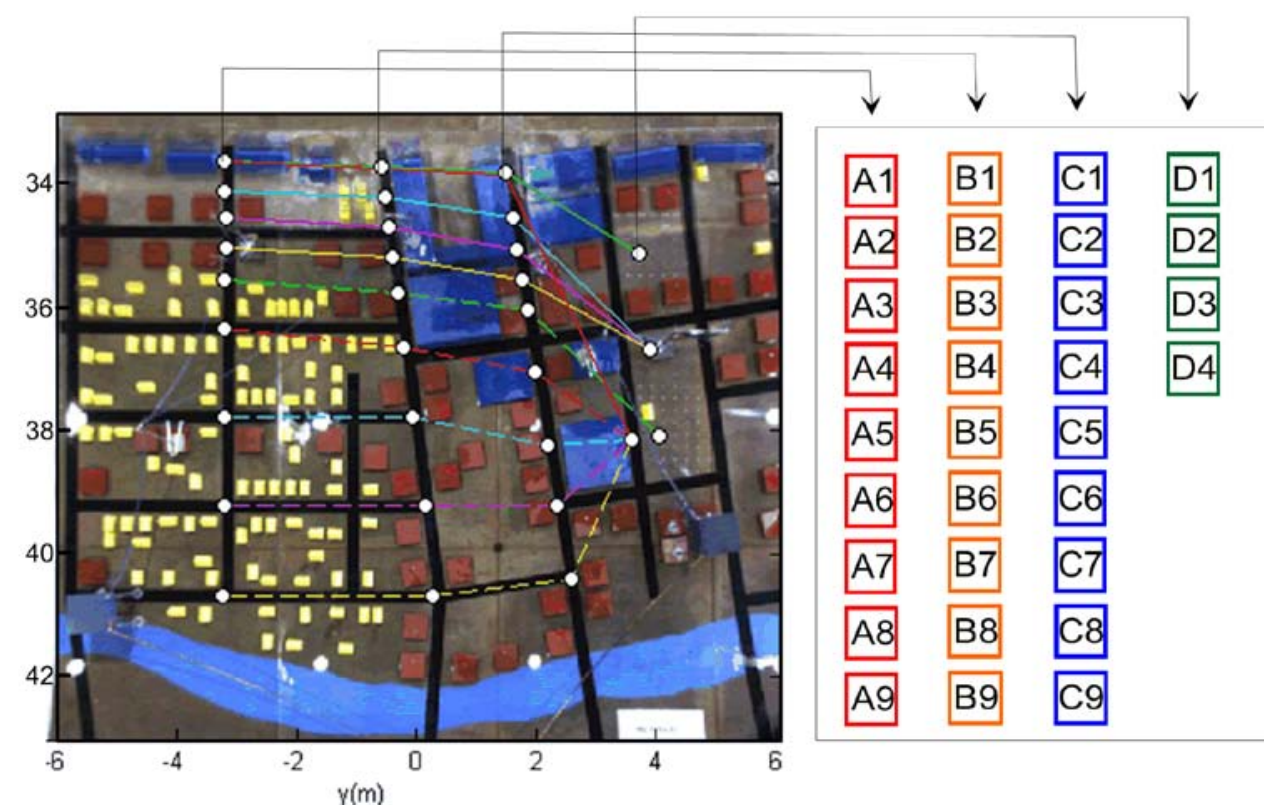

Figure 3. Instrument location along the streets. Lines in the left hand side photograph are the measurement positions of four pairs of USWGs and ADVs at each trial. 


\section{EXPERIMENTAL RESULTS}

Figure 4 shows an example of summarized data set. At the top panel of the figure, black line is wave board displacement. This displacement is different from that for generating conventional solitary wave and was designed to maximize the water mass for magnifying inundation. The blue line of the top panel is the free surface elevation measured by wave gage mounted on the wave board. The second panel from the top shows the free surface elevations at flat bottom (WG1) and on the slope (WG3). Inundation elevations at A1 and A3 are in the third panel from the top and those data were obtained by averaging several repetitions. The data indicated time lag between two sensors and inundation height difference as the tsunami travels landward. The bottom panel shows the horizontal fluid velocities at A1 and A3 measured by using ADVs.
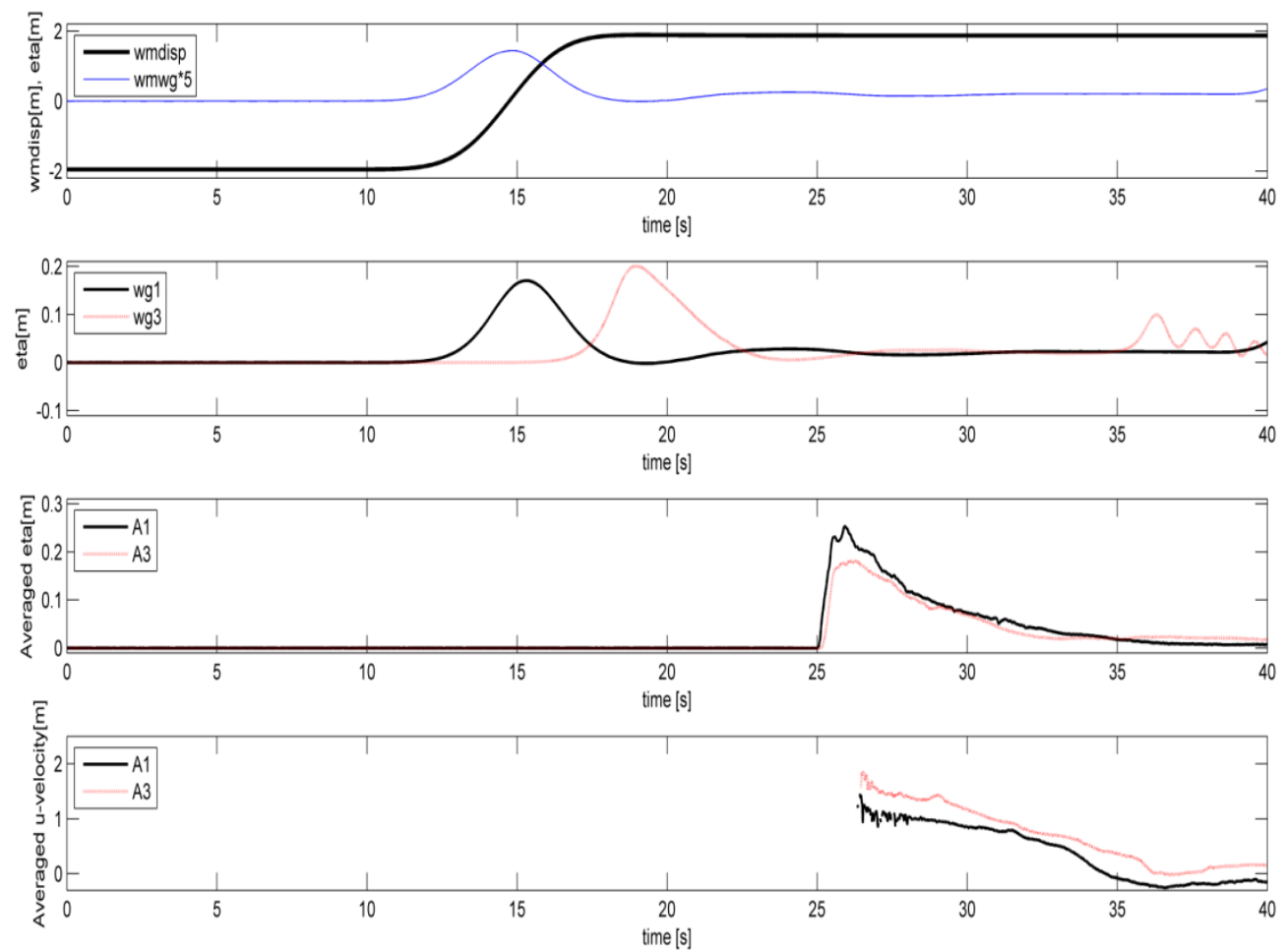

Figure 4 An example of time series data including wave board displacement, free surface elevations, and horizontal fluid velocities.

Figure 5 shows the time history of the free surface elevation measured at all the locations of city area by using USWGs. This figure proves that inundation heights decrease as tsunami travels landward.

The horizontal fluid velocities at all locations are show in Figure 6. As shown in the figure, ADV data failed to collect data at the leading edge of the wave because the leading edge contains large portion of air bubbles that interferes velocity estimate from the sensors. However, in order to estimate momentum flux, the time series of both free surface elevation and horizontal fluid velocity without any missing part. Momentum flux is usually defined as the product of inundation height $(h)$ and horizontal fluid velocity squared $\left(u^{2}\right)$ as show in equation 1.

$$
\text { Momuentum flux }=h \times u^{2}
$$

In order to obtain the horizontal velocity component near the leading edge of the wave, video image data were used. In the previous study in this experiment (Ruben, et al., 2011), high resolution video image data were collected by using Argus camera. They successfully tracked leading edge of the breaking wave using the intensity of image. Using those results, inundation speed of the leading edge can be estimated considering the time steps of images. And then we interpolated missing part of the velocity data between the leading edge and $\mathrm{ADV}$ data. 


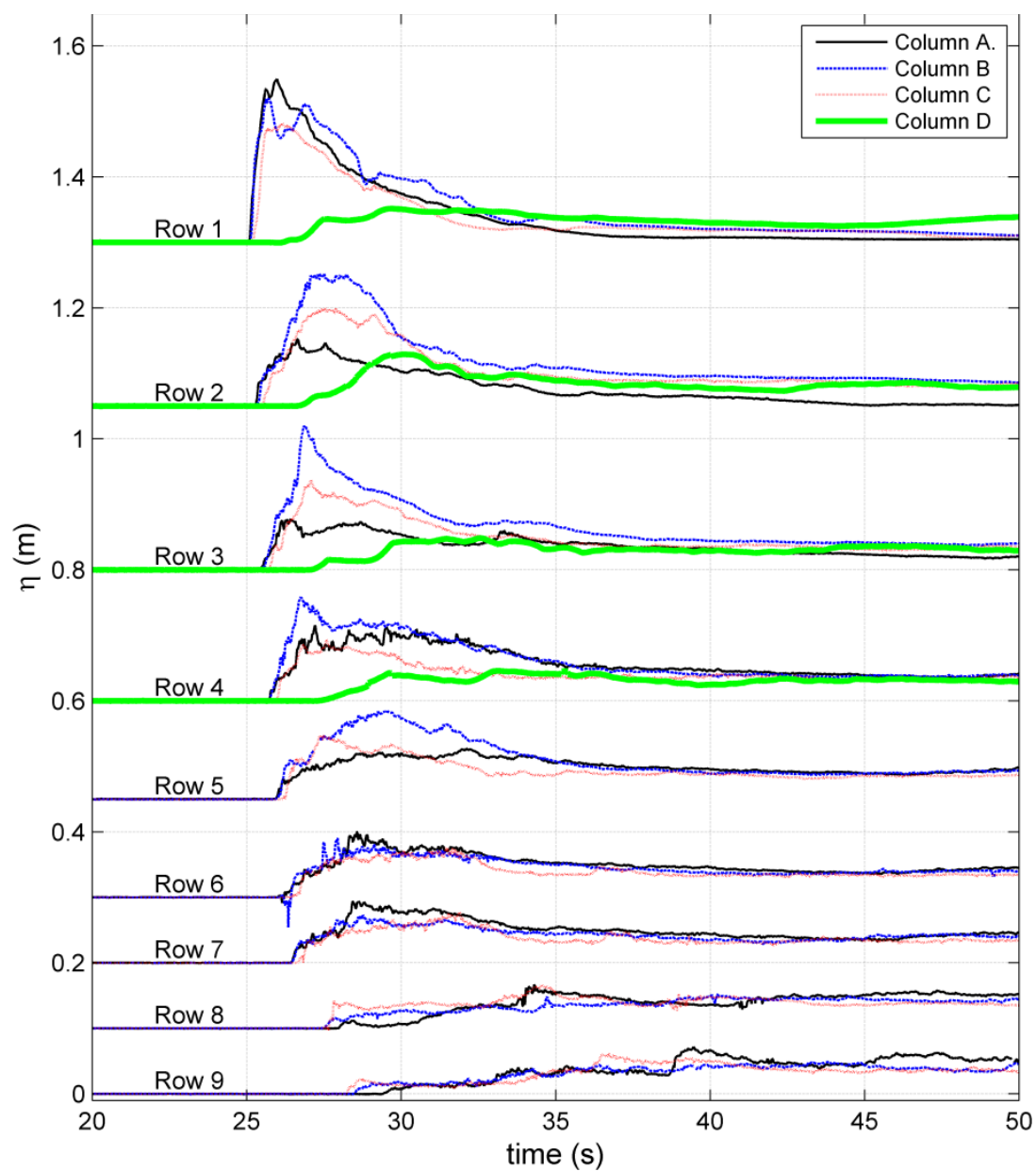

Figure 5. Inundation height as a function of time measured along the street by using USWG.
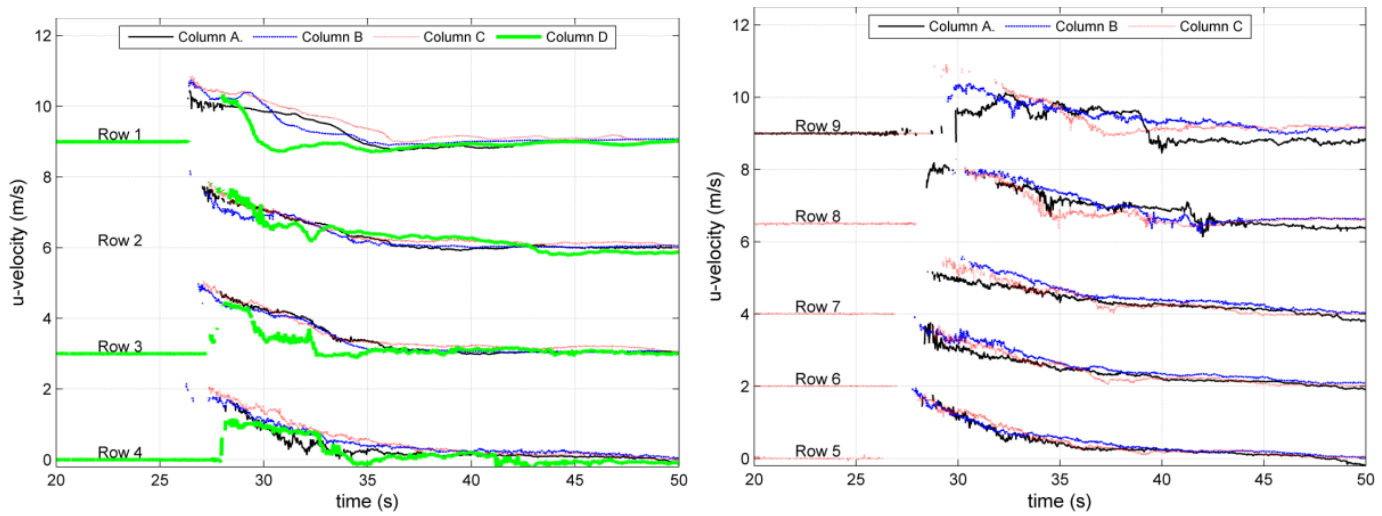

Figure 6. Horizontal fluid velocities as a function of time measured along the street by using ADVs.

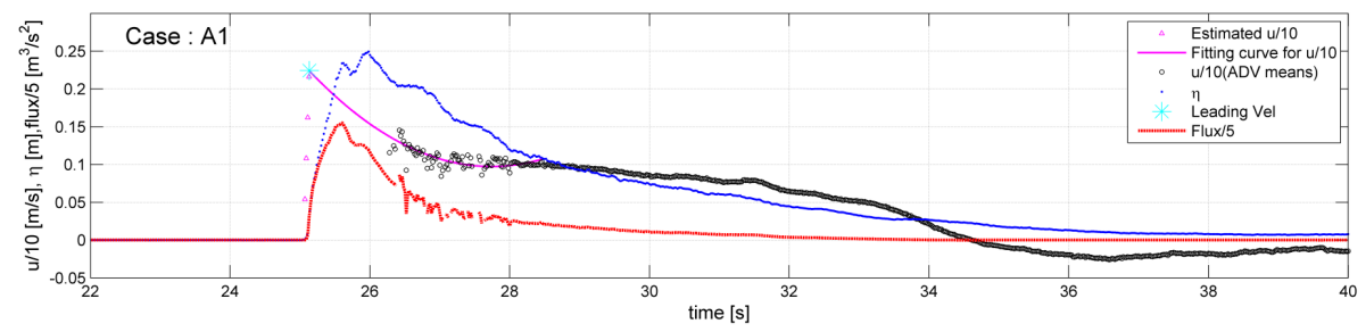

Figure 7. An example of horizontal fluid velocity interpolation using video image data and ADV data, and estimated momentum flux at $A 1$. 
Figure 7 includes the result of this estimate for horizontal fluid velocity as well as inundation height and estimated momentum flux. Blue line is inundation height and black dotted line is horizontal fluid velocity data. Cyan asterisk is estimated horizontal velocity of leading edge from the video image data. The pink line indicates interpolated horizontal fluid velocity. Using those values, momentum flux was successfully estimated as shown in the figure (red line).

Figure 8 shows the time history of momentum fluxes at all measurement locations.

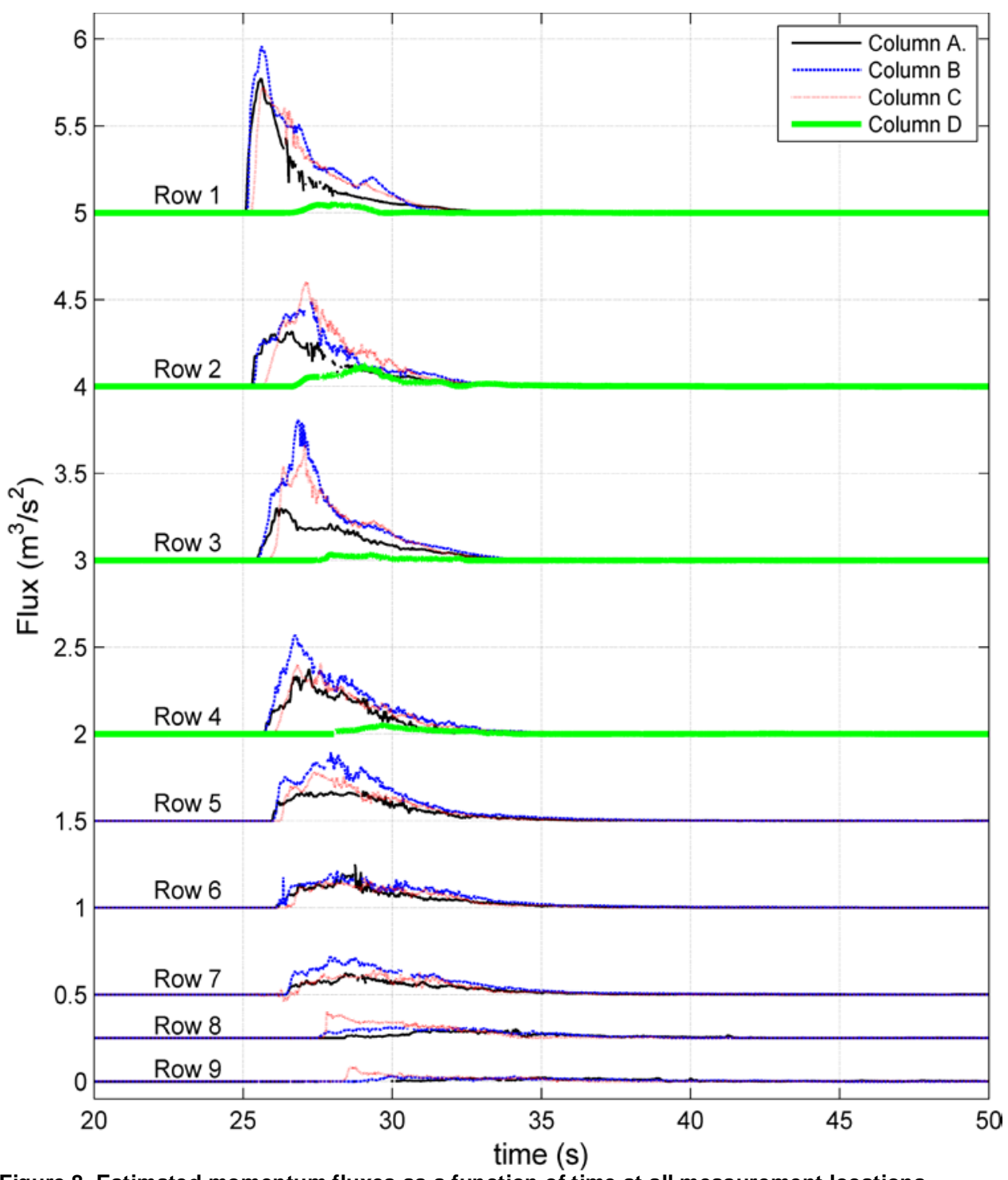

Figure 8. Estimated momentum fluxes as a function of time at all measurement locations.

Using these data, maximum inundation heights and maximum fluxed at each location were estimated and plotted along the cross-shore direction in Figure 9. In this figure, maximum inundation height at C1 is smaller than that at A1 and B1. This may be because the seal wall in front of C1 slightly functioned in protecting wave. However, the inundation height at column A decreased rapidly compared with column $\mathrm{C}$ and D because column $\mathrm{C}$ and $\mathrm{D}$ were the street as waveguides composed of the buildings as shown in Figure 3. Therefore, tsunami propagated without severe spreading along the street. However, column A and D were relatively open area behind the building located at waterfront so that waves were spread out as soon as passing through the first building.

The lower panel of Figure 9 shows the maximum fluxes along the streets. The cross-shore variation of maximum flux showed similar trend to the maximum inundation height variation. However, maximum flux variation at column B and $\mathrm{C}$ were similar and larger than that at column A which is different results in terms of maximum inundation heights. This result explains that the horizontal fluid velocity may give a larger effect on momentum flux than the inundation height does. 

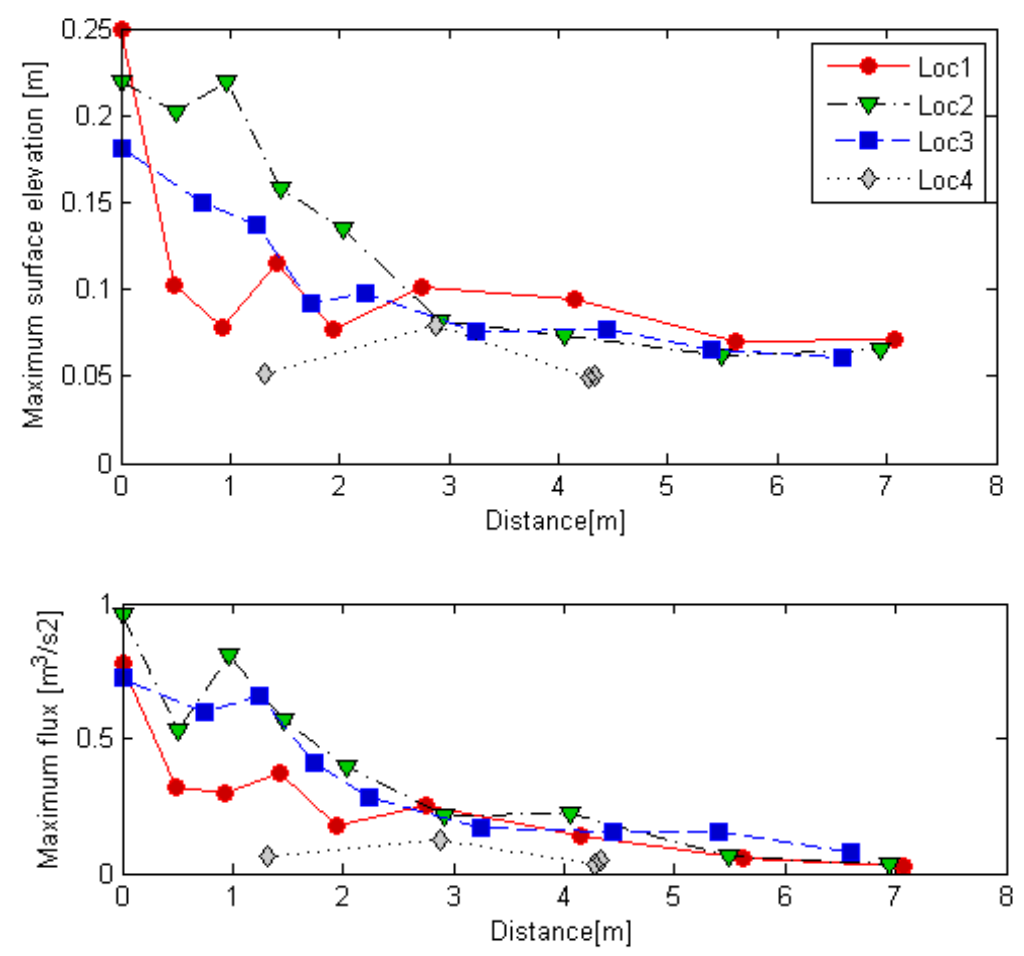

Figure 9 Cross-shore variation of maximum inundation height (top) and maximum momentum flux (bottom).

\section{NUMERICAL MODELING}

A three-dimensional large eddy simulation (LES) model was employed to predict tsunami inundation phenomena. 2PM3D (one-filed model for immiscible TWO-Phase flows) was developed by Lee, et al. (2010). The model is based on the Navier-Stokes solver and used large eddy simulation method for turbulence modeling. Volume of Fluid (VOF) method was used to track free surface. This model has been tested fluid-structure interaction and sediment transport.

In this study, computational domain covered entire area of wave basin (from the wave paddle to the end wall). Variable grid size was applied to the computational domain with the cross-shore grid size (dx) of $0.4 \sim 0.1 \mathrm{~m}$, alongshore grid size (dy) of $0.1 \mathrm{~m}$, and vertical grid size (dz) of $0.1 \sim 0.02 \mathrm{~m}$. Tsunami generation method of this model was previous based on the conventional solitary wave. However, in this study, tsunami generation was modified to use wave board speed and water surface elevation on the board because full stroke error function was used to generate tsunami in this experiment instead of solitary wave.

Figure 10 shows a snap shot of the preliminary numerical model result. Inundation pattern in the numerical model showed qualitative agreement compared with experimental result. The numerical simulation well captured reflected wave near the sea wall and hotels along the beach, irregular pattern of inundation along the street. Also the model result showed that an area behind the parking garage of U-shaped hotel is sheltered from high speed bore, which showed similar result from the experiment. The preliminary run only compared with experimental data in column A and B.

Comparison between numerical simulation and the experimental result of inundation height along column A was shown Figure 11. The figure showed normalized inundation heights since the result of preliminary run slightly over estimated offshore tsunami height and future modification is necessary in wave generation. Those figures show that the numerical model predicted qualitatively well compared with the experimental result but inundation height near leading edge of the bore overestimated at A2 and A3.

Figure 12 shows the cross-shore variation of inundation heights along the column A and B estimated from both the numerical simulation and the experiment. As shown in the figure, numerical simulation of maximum inundation heights from the row 1 to 5 showed good agreement with those 
estimated from the experiment. Therefore, this model may be capable of estimating the kinematics of tsunami inundation but the modification of wave generation will be necessary.

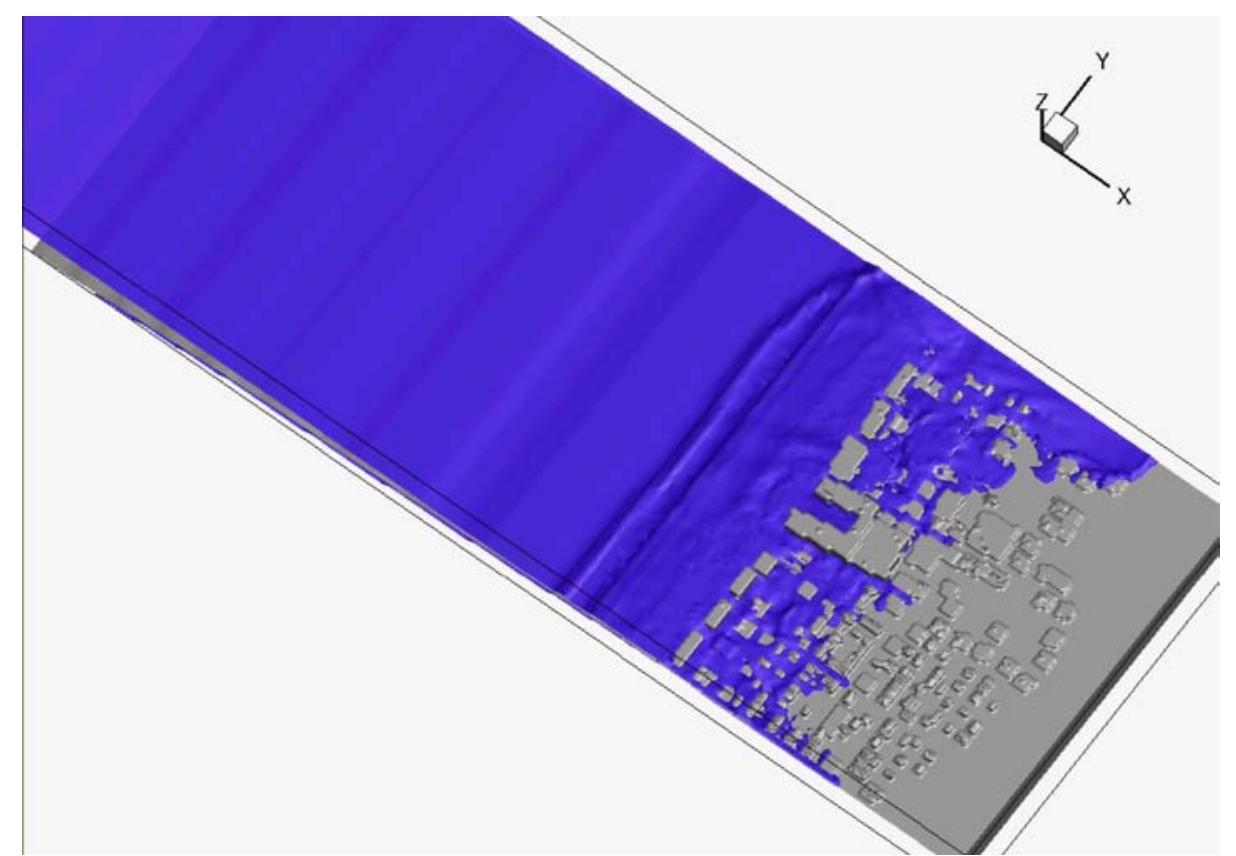

Figure 10 An orthogonal view of tsunami inundation simulated by the numerical model (2PM3D). Column A
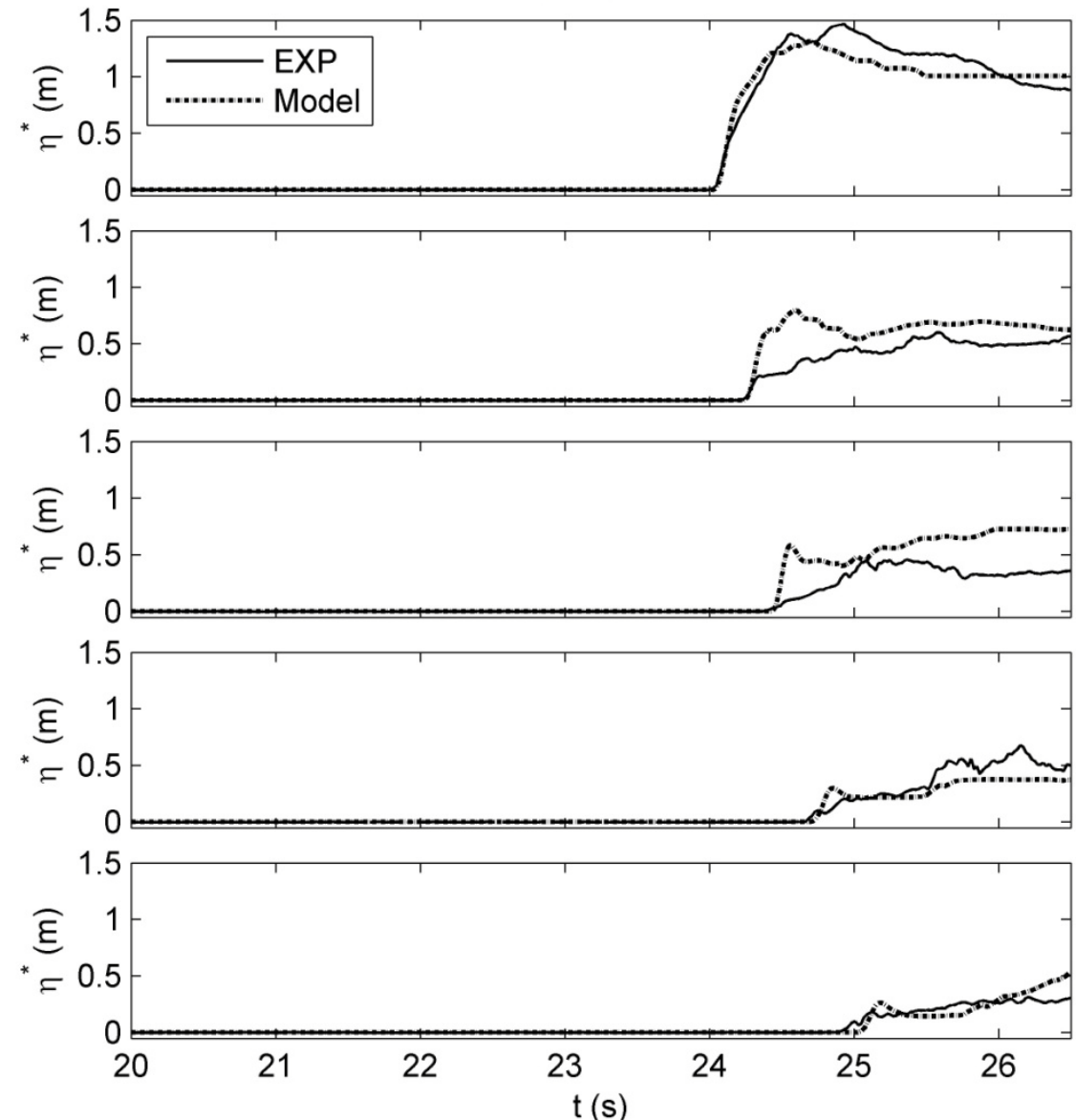

Figure 11 Comparison between numerical simulation and laboratory experiment in terms of time history of inundation heights along the street A (A1 $\sim 5$ from the top to the bottom). Solid lines are the experimental results and dotted lines are the numerical model results. 

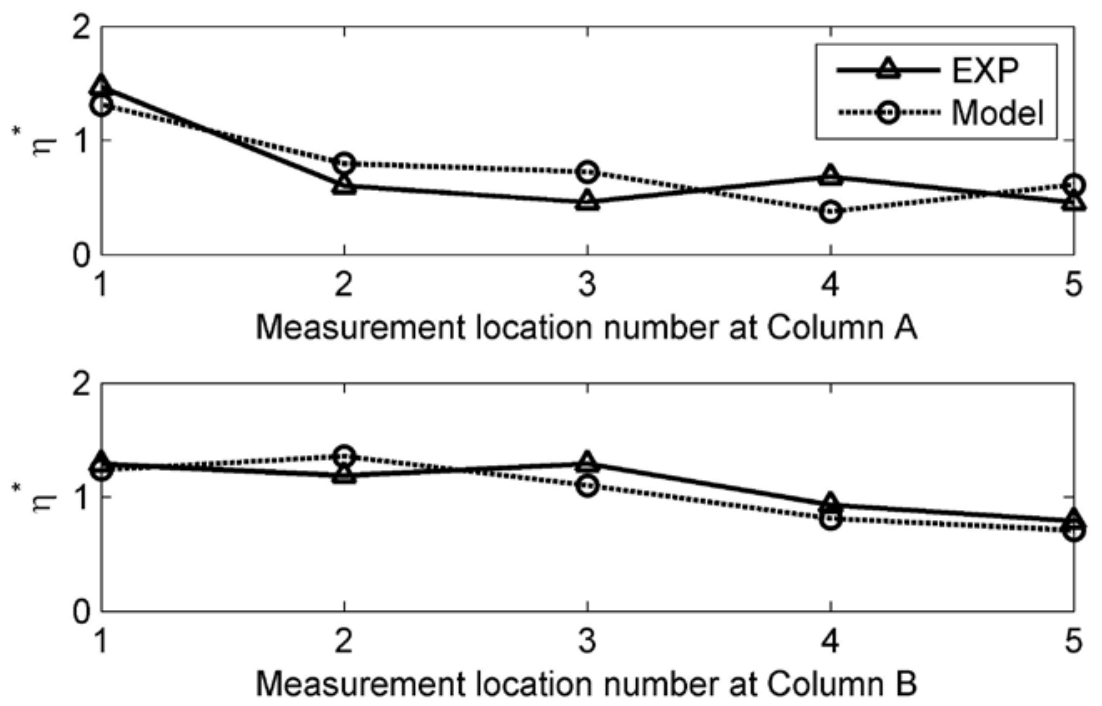

Figure 12 Comparison between numerical simulation and laboratory experiment in terms of maximum inundation heights along the street $A$ and $B$. Solid lines are the experimental results and dotted lines are the numerical model results.

\section{CONCLUSIONS and DISCUSSIONS}

Three-dimensional laboratory experiments and numerical simulations were conducted to understand mechanism of tsunami inundation. The synoptic experimental data set was used to test advanced numerical model, 2PM3D, and will be used to verify other numerical models.

The conclusions from the present study are:

- Maximum inundation height appeared in A1 but maximum momentum flux was in B1.

- Maximum horizontal velocity may be a key factor for estimate of force on the building because it gives more effect on momentum flux than inundation height.

- Both maximum inundation height and maximum flux decreased rapidly along the column A compared with the column B \& C due to the configurations of building.

- Numerical model results qualitatively agreed with experimental results in terms of inundation height. In the future, vertical distributions of horizontal velocities and pressures from the model results will be used to estimate tsunami forces acting on the structures.

\section{ACKNOWLEDGMENTS}

This work was supported by the Regional Innovation Center Program at Kwandong University of the Ministry of Knowledge Economy and a Manpower Development Program for Marine Energy by the Ministry of Land, Transport and Maritime Affairs (MLTM). The Tsunami Facility is supported by the Network for Earthquake Engineering Simulation (NEES) Program of the National Science Foundation under Award Number CMMI-0402490.

\section{REFERENCES}

Baldock, T.E., D. Cox, T. Maddux, J. Killian, L. Fayler. 2009. Kinematics of breaking tsunami wavefronts: a data set from large scale laboratory experiments. Coastal Engineering, 56, 506-516

Cox, D., T. Tomita, P. Lynett, and R.A. Holman. 2008. Tsunami inundation with macroroughness in the constructed environment, Proc. 31st International Conference on Coastal Engineering, ASCE, $1421-1432$.

Lee, K.-H., N. Mizutani, Y.-K. Kang. 2010. Applicability of 3D Numerical Wave Tank to Wave Deformation due to A Slit-Type Caisson Breakwater with Complex Geometry. Annual Journal of Civil Engineering in the Ocean, JSCE, 26 , 69-74. 
Lynett, P.J. 2007. Effect of a shallow water obstruction on long wave runup and overland flow velocity. J. of Waterway, Port, Coastal and Ocean Engineering, 133 (6), 455-462.

Rueben, M., R. Holman, D. Cox, S. Shin, J. Killian, and J. Stanley. (2011). Optical measurements of tsunami inundation through an urban waterfront modeled in a large-scale laboratory basin. Coastal Engineering, 58, 229 - 238.

Tomita, T., K. Honda, and T. Kakinuma. 2006. Application of three-dimensional tsunami simulator to estimation of tsunami behavior around structures. Proc. 30th International Conference on Coastal Engineering, ASCE, 1677-1688.

USGS Tsunami Pilot Study Working Group. 2006. Seaside, Oregon Tsunami Pilot Study Modernization of FEMA Flood Hazard Maps. Open-File Report 2006-1234. US Department of the Interior, US Geological Survey. 